\title{
Urbanization processes and practices of smart city as factors influencing youth's social values
}

\author{
Larisa Vlasenko ${ }^{\mathrm{r}^{*}}$ and Irina Ivanova ${ }^{2, *}$ \\ ${ }^{1}$ Moscow State University of Civil Engineering, Yaroslavskoe shosse, 26, Moscow, 129337, Russia \\ ${ }^{2}$ Financial University under the Government of the Russian Federation, Leningradsky pr. 49, \\ Moscow, 125993, Russia
}

\begin{abstract}
In the article, the co-authors analyze the formation of social values in young people in major cities, because their environments produce a direct impact on the choice of moral benchmarks and behavioral models. Personalities develop in the context of communication contacts, and the latter have specific features in megalopolises. The co-authors provide the findings of the phased opinion poll, conducted in 2011 - 2016, among the students of several Moscow universities. The mission of the poll was to identify the extent of the young people's satisfaction with the urbanization processes and the outspread of Smart City practices. The analysis has proven that the system of values, maintained by young people, is heavily influenced by the urban environment and the processes underway in it.
\end{abstract}

\section{Introduction}

A person is the backbone of an extensive multilevel system known as the environment. According to D. Markovic [1], professor of the Belgrade University and Doctor of Sociology, the notion of the "human environment" has natural and artificial (public) components, employed by the humans to fulfill their potential. He believes that the human, an active social being, fulfills his/her potential with the help of the public component of the human environment. Numerous Soviet and Russian researches were focused on the study of the human environment. N.F. Reimers, F.R. Shtilmark [2], L.V. Maksimova [3], and others analyzed the environmental structure.

In his description of the human environment, N.F. Reimers split it into several subsystems, including (1) the natural environment, (2) the quasi-natural environment (the environment developed by the agricultural machinery), (3) the artificial environment developed by humans, and (4) the social environment.

According to N.F. Reimers, the artificial environment encompasses the whole world, created by the human activities (the cultural and architectural environment, roads, transport, et.). It needs ongoing renovation and it decays without any proactive maintenance. On the whole, the artificial environment consists of all man-made material objects. [4]

The society and varied public processes, including the cultural and psychological climate, generated by humans as a result of their mutual influence, represent an important

Corresponding author: vllv@inbox.ru 
component of the environment. N.F. Reimers determined a dependence between the cultural and psychological climate and material, information, and energetic drivers (affluence, civil freedoms, confidence in the future, availability and accessibility of cultural and material values, availability of the social and psychological space), etc. According to the author, all the above subsystems must be preserved, and the elimination of any of them is impossible, as it may produce an adverse impact on the man.

L.V. Maksimova, a researcher of the human environment, also thinks that it has several components, including (1) the natural environment (biotic, abiotic), (2) the anthropogenic (technogenic, social) environment, (3) the living environment (social, recreational, production).

We believe that this structure's most important component, which determines the life and activity of a man as the subject of research in social and anthropogenic ecology, is the "living environment". It has three varieties: (1) the social environment, (2) the production environment, (3) the recreational environment.

The influence of the environment on the man has been the subject of research for a long time, and, as a consequence, it has its characteristics, properties, and qualities have been exposed to thorough research. Several Russian researchers have studied this problem in detail. $[5,6,7]$

The core mission of our research is to identify the influence, produced by the environment of a present-day city, on the formation of social values in young people. [8] The intensifying aggression of a contemporary megalopolis transforms their worldviews, alters the patterns of their behavior, and shifts the foci of their lives. Presently, there is a need to study the link between the characteristics, qualities, and properties of the environment and the needs of humans, the society as a whole. The objective is to find out the extent of compliance between the environment and human needs, or to identify the degree of environmental "comfort" or "discomfort".

The willingness of the man to be successful accelerates the tempo and rhythm of life. Accelerated lifestyles are typical for young men. The youth, being the most mobile population stratum, do everything in their power to leave for the city, the megalopolis, to get rid of their parents' care, to become independent and to take care of themselves. Changes in the place of residence cause young people to get transferred to different educational institutions, where they get trained for the professions which will be in demand in the urban environment.

The analysis of migration processes has proven that the youth migration has developed into the most complex social phenomenon. Young people hunts for numerous and versatile impressions; they build their lives around them; their impressions determine their lifestyles. Nowadays the majority of young people prefer living in the cities, especially in major megalopolises. When moving to new places, young people expect their new home localities and environments to have some cultural background that they may find appealing. This social and demographic group of young migrants is highly adaptive, although sometimes they cannot duly grasp the impulses generated by the urban environment.

In this work, the co-authors reflect upon the strengths and risks, accompanying urbanization processes, and the life in the present-day virtual environment of a megalopolis.

\section{Methods}

The main objective of our research is to identify the nature and intensity of the influence, produced by the urban environment on the formation of social values in young people. Towards this end, in 2011 - 2016 the Moscow State University of Civil Engineering, together with the Financial University under the Government of the Russian Federation 
conducted a sociological survey, including a questionnaire-based written opinion poll. The poll was conducted among the two target groups.

The first target group was composed of full/part time students, who resided in Moscow and its satellites and majored in different areas of knowledge. The second target group was composed of full time bachelor students, who did not reside in Moscow. The total number of respondents was equal to 165 .

We employed the questionnaire to find out:

- the extent of the students' satisfaction with their personal and professional selfdetermination;

- the significance of this type of education for students and the extent of their acceptance of this terminal value;

- the nature of changes in the values of second group students under the influence of the urban environment;

- what students know about the processes occurring in the urban environment;

- how students perceive "urban cities" and virtual interaction.

The poll (the questionnaire) and the document analysis method were employed in the course of the primary research.

\section{Results}

The findings of the opinion poll have revealed that education is a most important terminal value, that it represents a value in itself, because it is connected with knowledge acquiring, satisfaction of cognitive needs and spiritual development. [9] It is noteworthy that, as for the second target group, the number of non-resident students, having particular specializations, exceeded $50 \%$ of the total number of students. It means that they had arrived to Moscow to enter this particular university, although their home towns had similar higher education institutions.

It is noteworthy that the willingness to get away from the familiar environment, to make an attempt to demonstrate personal independence and strengths to those who do not leave their homes (villages or little towns) is a strong driver for entering universities in major megalopolises. This is how young people demonstrate their success and ambition.

Big cities attract you people by the opportunities they offer. Young people believe that a megalopolis offers extensive opportunities for self-fulfillment. The majority of our respondents from the second target group (89\%) think that they have made the right choice.

Despite the fact that we did not measure the extent of activity of the respondents in the course of our research project, we have identified that young people turn more active after their moving to the capital. They are keen on their self-confirmation; they do their best to study well and to participate in student research projects; they get involved in public and leisure activities (they participate in humour competitions, sports and science events, participate in the activities of the student trade union).

In the course of the research we discovered that the "aggressive" urban environment transforms the social values of young people. Some of our respondents resist the influence of the urban environment (15.0\%), while others tend to demonstrate conformity, and the competitive environment forces young people to prove their identity to the environment by getting excellent marks at the university.

When assessing the urban environment or one of its components, "the living environment" (L.V. Maksimova), the students distinguish its benefits more often than not; they speak of its comfort and tend to ignore its negative influence on the man (including noise, dirt, polluted air, numerous social contacts). We think that their approach is easy to explain by the peculiarities of their perception of this situation, the potential and the vitality of this special demographic group. 
It is common knowledge that numerous social contacts and the social environment of a big city cause emotional overloads; urban residents suffer from mental strain and emotional stresses [10], which make them more aggressive and raise the level of conflictogenity in the society, thus, changing its qualitative nature. A person, living in the huge space of a megalopolis, often feels lonely amidst numerous other residents; therefore, he generates new emotional barriers to stay away from the society. The risk of the big city's influence is particularly pronounced among young people.

We identified these phenomena among our respondents, although they were insignificant (12.0\%). To our mind, this finding can be explained by the fact that freshmen are usually satisfied with their environment. They have attained their interim goal; they are willing to study and to fulfill themselves in the future.

The formation of these systems of values, as a whole, and social values, in particular, is a strategic objective that sets the stage for such areas as upbringing, education and culture. Ethnic norms, moral ideals and ambitions, determining the system of human values, originate from families, develop in the social environment and at educational institutions, on the basis of the influence produced by positive examples and images; they serve as the basis for the formation of a spiritually developed, strong and creative personality, capable of making independent decisions.

Several questions served to identify the basic social values and systems of values. Both the first target group (residents of megalopolises) and the second one (residents of rural areas and small towns) proactively attain their objectives. Being university students, many students $(32 \%)$ think about getting supplementary knowledge (training courses, second degrees) to be more flexible in the labour market. The student's purpose of existence consists in his/her personal self-fulfillment (54\%), material welfare $(30 \%)$ and family happiness $(16 \%)$. The respondents realize the value of education as a means of social mobility.

Each day, the life of a young man is full of varied impressions. An urban resident draws them from the environment. Residential housing is quite convenient in the cities, where construction is very intensive, the service industry is very advanced, and transport accessibility is high. These factors represent evident strengths of contemporary megalopolises. These positive phenomena, typical for the urban environment, cannot help attracting young men to big cities.

The allure of the urban "living environment" goes up for young people, as major megalopolises (including Moscow) are now introducing the "smart City" concept. The mission of this concept is to improve the efficiency of urban services and streamline their communications to decrease the burden on urban services. However, are "smart cities" clearly positive?

The founding principle of a "smart city" is the incorporation of information technologies and devices into the urban environment. There is no doubt that this approach helps to improve the system of management/interaction between the state and the society, boosts the quality and efficiency of urban services, and to qualitatively improve the lives of residents. It is noteworthy that the main assets of a smart city include people, processes and technologies. However people do not always find it easy to get adapted to the changing environment.

Today the "smart city" concept has penetrated into numerous areas of living in a megalopolis: systems of video surveillance, public services, development of an intelligent transportation network, electronic police, distance education, electronic healthcare, etc. Therefore, a "smart city" is a strongly integrated system.

The students polled in the course of the research treat these changes as positive. The majority of the respondents in both groups $\left(1^{\text {st }}\right.$ group $-87.0 \%, 2^{\text {nd }}$ group $\left.-91.0 \%\right)$, welcome the changing "living environment" in Moscow. The $1^{\text {st }}$ group of students 
(Muscovites) highly appreciates electronic public services and an intelligent transportation network. The $2^{\text {nd }}$ group of students (natives of small towns residing in dormitories) appreciate "smart stops" demonstrating the time to arrival of a public vehicle, the beauty and comfort of leisure areas.

On the whole, intensified urbanization, which needs administrative and technological support to ensure the maximal safety of the urban life, is quite positive, according to our respondents.

In the meantime, our respondents realize that a human being is part of nature, and his/her environment must comprise natural and artificial (societal) elements for the human being to be able to fulfill him/herself comprehensively.

\section{Discussion}

According to several researchers, Greek philosophers Plato and Aristotle were among the first thinkers who raised the issue of the role and significance of cities in the life of the humankind. This problem enjoyed coverage in Europe, North America and Russia in the late $19^{\text {th }}$ - early $20^{\text {th }}$ centuries, when the researchers first registered the growing numbers of the urban population, accompanied by new problems.

Back then, urbanization was considered as a complex social process, which caused the development of cities and the increase in the share of the urban population. M. Weber's book "The City" marked an important stage in the urban science. In this book, the author analyses the city from the standpoint of social science, thus, developing urban sociology, a new branch of social science. Urban sociology was founded by A. Park, L. Wirth and E. Burgess, the researchers of the Chicago school of sociology.

The complexity, ambiguity and changeability of the city as the subject of research changed the idea of urbanization process in the second half of the $20^{\text {th }}$ century. Back then, urban development problems enjoy more attention, as new settlement patterns emerged, including rururbanization and suburbanization, the population concentration went up in megalopolises, and the quality of the urban environment changed.

There is no doubt that the extent of urbanization is a factor of growth, development and welfare of any country. Nevertheless, we can consider urbanization both as a positive and negative factor of economic development in any society, because it may cause the following problems:

1) Ecological problems (urban living and the quality of the urban environment turn more complex; climatic changes and environmental pollution aggravate) [11];

2) Demographic problems (high concentration of residents);

3) Economic problems (due to the unofficial activities in the cities);

4) Spatial problems (spatial planning, namely, urban planning ignores the opinion of local residents; public hearings are fictitious, etc.);

5) Cultural (human behavior standards transform; the system of values changes), etc.

Some research works focus on the study of a man in a city as a phenomenon of culture, as well as the influence of cities on men/societies.

The attempt to systemize the problems of cities and urban environments, to perform their comprehensive analysis, and to consider the impact produced by the environment on the man, reveals the unavailability of any consistent methodological basis. There is a need to identify the links between urban science, urban sociology and architectural sociology. Several domestic and foreign researchers have been working at this problem, including L. Mumford, [12], J. Jacobs [13], K. Lynch [14], etc., in Russia L. Kogan, [15] ,V. Glazychev [16], and V.B. Vilkovsky [17] studied this problem. The scope of problems, covered in this article, enjoys little attention in the contemporary Russian research community. 


\section{Conclusions}

L. Mumford considered the city a great human creation, as if "offers a maximal number of opportunities for the humanization of the natural environment and for the naturalization of the human (cultural) heritage". The city satisfying the maximal set of human needs, is characterized by fast tempo and unpredictability, and young men usually live very fast, they manipulate the information flows and the fast changing reality. This is particularly true for the environment of a big city, that offers maximal opportunities for development.

Our sociological survey has generated the following findings:

1) Young people are satisfied with their personal and professional self-identification. They realize the value of their education for their future;

2) Young people are aware of the urban social processes, they enlist the problems experienced by the urban environment, but they are not likely to overstate them;

3) The basic values, cultivated in families, at educational institutions do not undergo any substantial changes if exposed to the influence of life in a megalopolis; they are merely reassessed by young people. In this case, the system of values does not undergo any comprehensive changes, only the top priorities and the hierarchy shift a little.

4) Young men welcome "smart cities" and virtual interaction.

The researchers have written a monograph [18] and research articles [19] covering the issues of their sociological survey.

\section{References}

1. D. Markovic, Social ecology (Prosveshcheniye Publ, 1991)

2. N.F. Reimers, F.P. Shtilmark, Specially protected natural areas (Mysl Publ, 1978)

3. L.V. Maximova, Evolutional and Historic Anthropoecology, 77 - 88 (1994)

4. Ivanova Z.I., Yudenkova O.V., Ishkov A.D., Shnyrenkov E.A. International Education Studies 8(5), 232-239 (2015)

5. V. Ilyichev, Biosphere compatibility: technologies for introduction of innovations. cities that develop humans (Librokom Publ, 2011)

6. V.L. Glazychev, A city without borders (Territoriya Budushchego Publ, (2011)

7. Khripko E. MATEC, 73, 07021 (2016).

8. Shnyrenkov E.A., Pryadko I.P. Procedia Engineering. 117, 325-330 (2015).

9. 9 Leontev M.G. MATEC, 73, 07005 (2016)

10. E. Romanova. Procedia Engineering, 165, 1176-1183 (2016)

11. I.A. Ivanova, Economic and psychological problems of economic decision-making in the context of global changes, 78-81(2015).

12. E. L. Mumford, The culture of the cities (Greenwood Press Reprint, 1981)

13. J. Jacobs, The death and life of great American cities (Random House, 1961)

14. K. Lynch, The image of the City (The MIT Press, 1960)

15. L.B. Kogan, Urbanization. Evolution of Research and Technology and the Working Class (Nauka Publ, 1972)

16. V.L. Glazychev, Architecture, 2 (21) (1978)

17. M.B. Vilkovsky, Sociology of the Architecture. "Russian Avantgarde» Heritage Preservation Foundation (Moscow, 2010) 
18. L.V. Vlasenko, I.A. Ivanova. Economics and entrepreneurship, 2, 710-714 (2016)

19. L.V. Vlasenko, I.A. Ivanova, The paradigms of personal and professional education of students: present-day challenges, 276 (SIMJET, 2015) 